\title{
Internet of Things-Based Concrete Curing Invention for Construction Quality Control
}

\author{
King-Chi Lo, ${ }^{1}$ Heung-Wing Terry Kwok, ${ }^{1}$ Ming-Fung Francis Siu (iD, ${ }^{1}$ \\ Qiping Geoffrey Shen, ${ }^{1}$ and Chi-Keung Lau ${ }^{2}$
}

${ }^{1}$ Department of Building and Real Estate, Faculty of Construction and Environment, The Hong Kong Polytechnic University,
Hung Hom, Kowloon, The Hong Kong Special Administrative Region of the 10 People's Republic of China (HKSAR), China
${ }^{2}$ Fong On Construction Ltd., 6/F, Kai Tak Commercial Building, 317-319 Des Voeux Road Central, Sheung Wan,
Hong Kong Island, China

Correspondence should be addressed to Ming-Fung Francis Siu; francis.siu@polyu.edu.hk

Received 18 March 2021; Revised 12 May 2021; Accepted 20 May 2021; Published 8 June 2021

Academic Editor: Hexu Liu

Copyright (C) 2021 King-Chi Lo et al. This is an open access article distributed under the Creative Commons Attribution License, which permits unrestricted use, distribution, and reproduction in any medium, provided the original work is properly cited.

\begin{abstract}
The efficiency of the traditional concrete curing process on site is low, due to the difficulties in providing continuous supervision and control of the curing environment, leading to considerable variation in the curing regimes experienced by different concrete pours. To enhance concrete curing practice, technologies have been harnessed which eliminate human involvement enabling more rigorous control of the environmental conditions affecting curing, but the potential for Internet of Things (IoT) technologies had yet to be explored in this context. This research study examined an IoT-based concrete curing control system based on sensor technologies invented for monitoring and controlling the moisture content of hardening concrete to the levels appropriate for good quality hardened concrete. Based on on-site experiments, the performance of this IoT-based method was compared with the performance of traditional curing methods. The results indicate that the system invented outperforms the traditional approach both in terms of concrete curing quality and time spent on supervision.
\end{abstract}

\section{Introduction}

Concrete is widely used in construction because of its versatility, strength, durability, and flexibility. To reach its best performance, proper concrete curing is required during the concrete hardening process, as the hydration reaction between water and cement takes place [1]. Both the moisture content within the concrete and the temperature, during hardening, are critical parameters determining the quality of the concrete $[2,3]$. The moisture content correlates to the degree to which all the cement particles are actually hydrated in the setting process, and the temperature determines the speed of the reaction. As such, to maintain suitable levels of hardening concrete moisture content and temperature, it is essential that the moisture content and temperature of the external air surrounding the hardening concrete, the surrounding environmental conditions, are continuously controlled. Any water loss by evaporation, which relates directly to wind speed, temperature, and humidity, must be avoided.
Concrete curing is the process by which the moisture content and temperature of fresh concrete is maintained $[4,5]$. The moisture content in fresh concrete is potentially reduced by evaporation. The critical factors, which govern the evaporation of water from fresh concrete [6], are ambient air temperature and relative humidity, concrete's temperature and moisture content, and wind velocity [7-10]. The rate of water loss by evaporation can be estimated using the ACI monograph (Figure1). The ACI monograph has been developed to enable estimating of the evaporation rate of the bleed water lying on fresh concrete surfaces [11]. The evaporation rate estimate is valid regardless of where the evaporation takes place and is applicable to the evaporation of bleed water and to evaporation from a moist/wet hardening concrete surface.

The rate of hydration reaction depends on temperature [12]. The higher the temperature, the faster the hydration process. Although the hydration process can be accelerated by high temperature, the early ultimate strength of concrete 


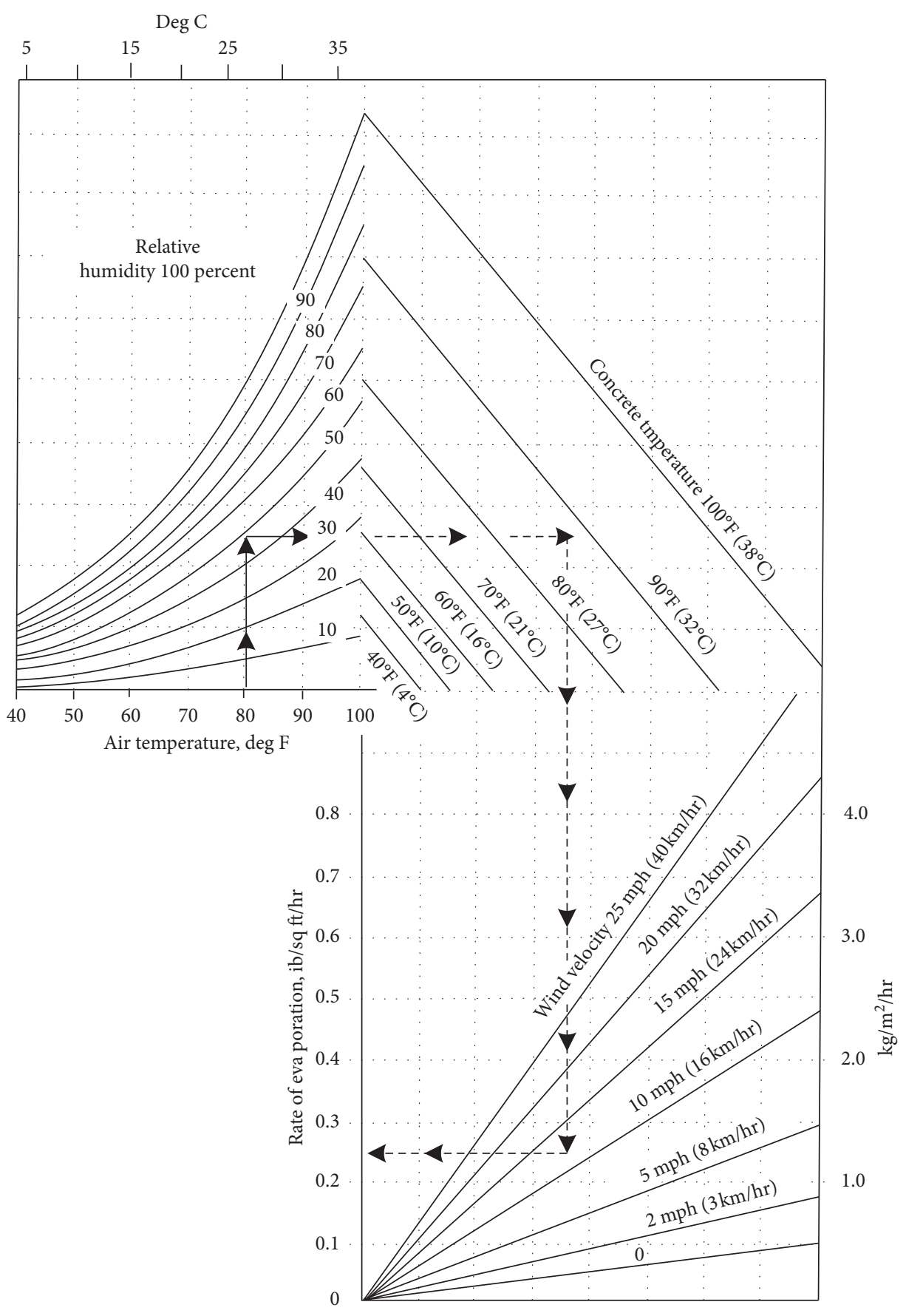

ACI monograph (Uno, 1998)

Figure 1: ACI monograph [6]. To use this chart, (1) enter with air temperature, and move up to relative humidity. (2) Move right to concrete temperature. (3) Move down to wind velocity. (4) Move left; read the approx. rate of evaporation.

is low due to incomplete development of the hydration process [13]. There are existing concrete curing methods which maintain the concrete moisture content and temperature at ideal levels consisting, among others, of immersion, ponding, sprinkling, and wet cloth covering $[14,15]$. However, the limitations of these traditional curing methods are the difficulties in supervising and controlling the required environmental moisture and temperature conditions [16-18].
Traditionally, environmental information is recorded daily by the construction team as well as the steps actually taken to cure newly placed concrete [19]. Obtaining an accurate master dataset, manually, in this fashion can be challenging and demanding because so much activity and record keeping is continually required on the typical construction site. Getting all this information to be both on time and accurate is very difficult to achieve [20]. A scandal on the Hong Kong Section of the Hong Kong-Zhuhai-Macao 
Bridge project revealed that manual record can be inaccurate, incomprehensive, and even fake [21]. Given the complex environment and conditions on site, monitoring work is always difficult to "fit in," requiring significant investment in time and human resources.

Because these problems remain unresolved, we were motivated to overcome the limitations of the traditional approach to concrete curing by inventing an IoT device, to automatically maintain the moisture and temperature of fresh concrete. The IoT device enables data recording and concrete curing operations to occur automatically, saving time and effort. Through the adoption and combination of three sensors, the devices can be used to monitor air temperature, humidity, wind speed, concrete moisture content, and concrete temperature. A water pump is also installed within the device for the spraying of curing water when required.

\section{Literature Review}

Gokhale et al. [22] wrote that the "Internet of Things (IoT) is a network of physical objects, such as devices, instruments, vehicles, buildings, and other items, with embedded electronics, circuits, software, sensors, and network connectivity that enable these objects to collect and exchange data." The IoT is generally defined as "dynamic global network infrastructure with self-configuring capabilities based on standards and communication protocols." The IoT is able to sense and control the physical world remotely through the integration of computer-based systems to increase the efficiency and accuracy of the activities concerned.

Arslan et al. [23] summarised 12 IoT application studies in construction. They concluded that IoT benefits the construction industry in decision-making, BIM integration, health and safety issues, progress tracking, and real-time monitoring. Safety due to accurate and efficient communication required strong progress tracking and real-time monitoring. One real-life application is to use an IoT wearable device which detects the health (heartbeat and body temperature) of construction workers. Any abnormal body conditions caused by construction accidents, say fever, will trigger the IoT device to alert of any unhealthy body condition.

A limited number of researchers have applied IoT technology to concrete structures monitoring. Taffese et al. [24] indicated the possibility of adopting IoT for structural condition assessment. An automatic system for monitoring concrete temperate, air temperature, and humidity ranges should enable the maturity of concrete and its strength to be predicted. Thus, a user-friendly Internet/mobile IoT system was invented for the purposes of monitoring the early stages of concrete hydration and hardening formation [24]. This paper reports on the subsequent study made of its performance in practice.

Scholars have already studied the possibility of adopting the IoT for digital concrete quality control. Ghosh et al. [25] first indicated the concreting process problems of (1) large amounts of waste [26]; (2) low productivity of concreting activities due to the high demands made on resources and management [27]; (3) insufficiency of concrete structures' durability and strength; (4) environment disruption affecting all the factors that associated the concreting. To tackle such problems, Ghosh et al. [25] established an IoT conceptual framework to automatically monitor the lifecycle of concrete, which requires the real-time monitoring of parameters such as temperature, moisture content vibration levels, and crack occurrences. These papers demonstrate the possibilities for the Internet of Things (IoT) to provide a digital concrete quality control capability (DCQC).

The most currently relevant research by Yang et al. [28] concerned his own invented IoT-based concrete curing system. The system applied the hydration heat release law to calculate theoretical water loss and to replenish that loss using a programmed fogging sprayer. The sprayer is controlled by a logic controller governed by an equation derived from Physics:

$$
\Delta t_{i}=\frac{q /\left(v_{i}^{e}-t_{s p}\right)}{\exp \left\{E_{a} / R\left[(1 /(20+273))-\left(1 /\left(T_{i}+273\right)\right)\right]\right\}},
$$

where $v_{i}^{e}$ is the equivalent instantaneous heat rate at the equivalent age, $T_{i}$ is the average temperature of the interval time $\left(t_{i}-t_{i-1}\right), t_{i}$ is the final age of time step $i, t_{i-1}$ is the initial age of time step $i, E_{a}$ is the activation energy, $E_{a}=$ $(33.5 \mathrm{kj} / \mathrm{mol})$ when $T \geq 20^{\circ} \mathrm{C}$ and $E_{a}=(33.5 k j+1.47 \times$ $(20-T) k j / \mathrm{mol})$ when $T<20^{\circ} \mathrm{C}, R$ is the universal gas constant, $R=8.3144 \mathrm{~J} / \mathrm{mol} / K, t_{s p}$ is the spray time in advance, $\left(T \Delta t_{i}\right)$ is the average concrete temperature during the time interval $\Delta t_{i}$, and $\Delta t_{i}$ is the chronological time interval.

To verify the curing function of the sprayer, Yang et al. [28] prepared two types of sample (Samples M and A) and a total number of 20 samples. Samples M represent manualbased cured concrete. Samples A are those controlled and cured by the IoT-based curing system. The result shows that the IoT-based curing system maintains a constant level of concrete moisture content. In contrast, Samples M indicate fluctuating humidity levels since the necessary curing activity is not always on time in responding to changes in concrete temperature.

Also to be noted is that the IoT-based curing system of Yang et al. [28] showed a better control of curing temperature than manual-based curing system. The fluctuations of surface temperature of Samples A and Samples M are $3^{\circ} \mathrm{C}$ and $8^{\circ} \mathrm{C}$, respectively. The rapid changes of surface temperature led to temperature differences between inner concrete and near-surface concrete, causing potential cracking due to the differential strains set up by the different expansions and contractions of adjacent layers of inner and outer concrete [29].

Yang et al. [28] also indicated that concrete could reach a high compressive strength under conditions of a rigorously controlled relative humidity and temperature. They highlighted that the manual-based curing limitation, particularly pointing out that the difficulty in ensuring constant and stable curing intervals between manual sprays, will result in a reduced quality of concrete. Since the IoT-based curing 
system helps to maintain stable concrete temperature, the risk of crack occurrence can be reduced leading to a higher quality concrete.

Kholia et al. [30] concluded that traditional water curing is generally more effective than membrane curing and accelerated curing in terms of water retention. Sprinkling and wet covering are more commonly used water curing methods on site with fewer limitations. However, sprinkling and wet covering are less efficient than ponding and immersion due to the strict concrete surface wetting and drying requirements and the considerable amount of labour needed. Thus, an IoT-based concrete curing device will be beneficial in improving the efficiency and quality of concrete curing and in replacing the complicated manual operations.

The IoT-based concrete curing system proposed by Yang et al. [28] applied the hydration heat release law as its working principle. Temperature and relative humidity sensors are used, and a track is kept on whether the humidity at the concrete surface is greater than $80 \%$. However, relative humidity is highly governed by wind, and curing concrete will often have a low relative humidity $(\mathrm{RH})$ in windy environments such as coastal sites. Sprinkling, of course, will keep the concrete wet but not contribute much the surrounding $\mathrm{RH}$, necessitating near-continuous ongoing sprinkling.

The past studies of use of IoT in concreting have included but were not limited to DCQC and auto-devices for concrete curing. However, the studies did not consider the effects of on-site wind speed on concrete curing. Thus, there is a research gap in that; the parameter, wind speed, has not been taken into account as a factor affecting curing performance. As a result, this research study involves a new IoT device which, with the aid of the AGI monograph above, automatically replaces any water lost from the concrete surface due to wind-induced evaporation.

\section{Methodology}

3.1. Invention of IoT Concrete Curing Device. The proposed IoT-based device is based on the ACI monograph variables. The parameters, concrete temperature, moisture content, air temperature, humidity, and wind speed, are considered in this research. To monitor those factors, the proposed IoTbased device is composed of 3 sensors, 1 programmable microcontroller, and 1 water pump. The working principle is to maintain the required moisture content by spraying water on the concrete surface at defined time intervals, so as to automatically maintain concrete surface dampness and temperature. The amount of spray water is calculated to fit the evaporation from the concrete surface according to the ACI monograph. This effectiveness of this system was then validated experimentally, making comparisons with different curing methods.

The four essential parameters affecting the evaporation rate consisted of air relative humidity $(\mathrm{RH})$, air temperature, concrete temperature, and wind speed. The values of these parameters were detected using sensors. The sensors first send signals to the microcontroller which then performs calculations and analysis. The microcontroller then sends signals to the water spray and controls the supply of curing water by adjusting spraying time.

All sensor data detected are shown on a connected computer for real-time monitoring purposes and decisionmaking throughout the process. The data can be further shared to distant connections through the IoT platform. Table 1 and Figure 2 show the model of sensors and devices used in the prototype [31-43].

3.2. Experimental Settings. The IoT-based sprinkling device aims to enhance the efficiency and accuracy of the traditional manual approaches and to provide real-time tracking of the process. Yang et al. [28] mentioned that sprinkling curing keeps the concrete surface moist. Also, the effectiveness of water curing is positively related to the total time spent with moist concrete. Therefore, the performance of sprinkling curing can be measured by comparing the efficiency of the maintenance of the surface dampness of the concrete.

There are three types of concrete curing (1) air-based curing; (2) manual-based curing; (3) IoT-based curing. The curing before and after the times of "final set" were tested using a manual-based method approach. Manual-based curing is not applied prior to the time of final set to avoid damage to vulnerable cement paste caused by the force exerted by any uncontrolled flow of water. Therefore, a plastic film was used in the case of manual-based curing before concrete final set. Theoretically, IoT-based controlled sprinkling can be applied before final set. The newly proposed IoT-based curing device sprays water at 10-minute (maximum) intervals to ensure a consistent concrete surface dampness. It is expected that the IoT-based curing replenishes bleed water evaporation loss before the final set and replenishes evaporated wet surface water loss following the final set.

The experimental hypotheses are as follows: there is no energy loss to the surroundings, no energy gain from radiation, no delay in recording times among the three concrete groups, and no additional water (including vapour) added; site temperatures and humidifies experienced are consistently identical for all three sets of concrete samples.

The mix materials used in the experimental samples are tabulated in Table 2. The information was retrieved from a typical concrete test report. An overview of the experiment is given in Figure 3. Details of Experiments A and B are given in Tables 3 and 4, respectively.

\section{Experimental Results}

Table 5 gives the concrete surface temperatures and dampness percentages according to the experimental procedures of Experiment A. Table 6 gives the concrete surface temperatures and dampness percentages according to the experimental procedures of Experiment B. Table 7 shows the time at which the manual-based method was applied in Experiment B. Table 8 shows the amount of water used by proposed IoT and manual approaches. The results trend is analysed in the "discussion" below. 
Table 1: Sensors and devices.

\begin{tabular}{lc}
\hline Sensor type(s)/devices & Sensor name \\
\hline Temperature and humidity sensor & DHT11 \\
Waterproof temperature sensor & DS18B20 \\
Anemometer (wind speed meter) & Anemometer wind speed sensor w/analog voltage output \\
Microcontroller & Arduino UNO Rev3 \\
Water pump & 5v DC mini water pump \\
\hline
\end{tabular}

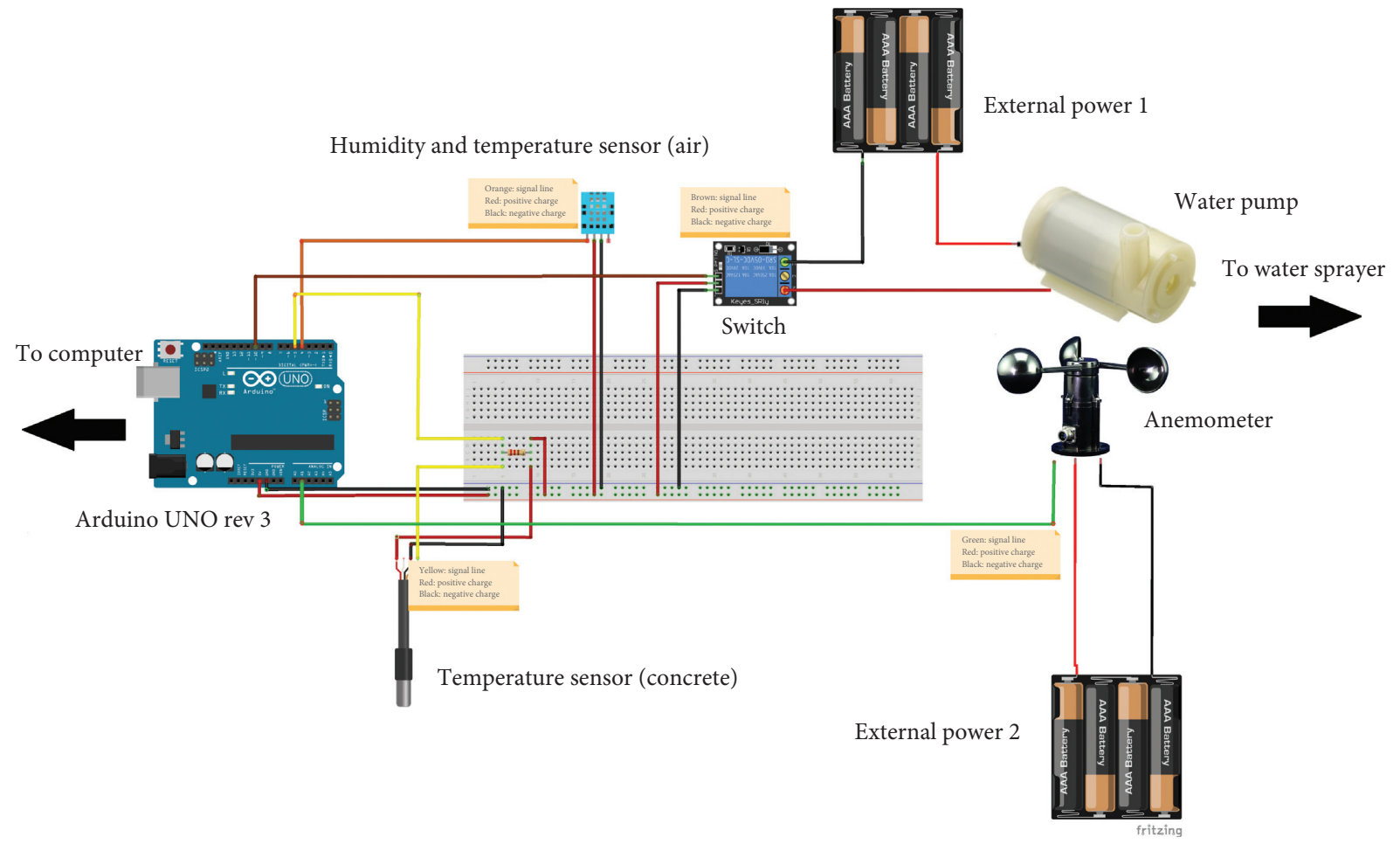

FIGURe 2: Devices assembly design.

TABle 2: Materials of the sample mixture.

\begin{tabular}{lc}
\hline Materials & Types \\
\hline Concrete & Ordinary Portland cement \\
Admixture & Pulverized fuel ash \\
Aggregate & $20 \mathrm{~mm} / 10 \mathrm{~mm}$ \\
W/C ratio & 0.45 \\
\hline
\end{tabular}

\section{Discussions on Experimental Results}

5.1. Experiment $A$. Figures 4 and 5 show the appearance of 3 sets of concrete samples at Time 225 minutes when the concrete had reached the designed final setting time. It is observed that bleed water has been completely lost for the manual-based cured sample, but the surface was smooth without any cracks (Figure 4). Cracks were observed on the surface of the air-cured sample (Figure 5) because the loss of bleed water caused drying out, plastic shrinkage, and cracking. The concrete surface, to which the IoT-based curing method was applied (Figure 6), was as smooth as that of the manual-based curing method without any cracks. It is concluded that the proposed IoT device successfully cured the concrete before final set.
Figure 7 shows the surface temperature of 3 sets of concrete samples. Firstly, it is observed that the surface temperature of manual-based curing is approximately $5^{\circ} \mathrm{C}$ higher than that for air curing and IoT-based curing, at $25^{\circ} \mathrm{C}$. This is due to the application of the plastic film for manualbased curing before final set. The heat released by the hydration process is trapped in the concrete. Secondly, the temperature was consistently kept at $20^{\circ} \mathrm{C}$ in the air-cured and IoT-based cured sample cases that the temperature remained steady means that the heat gain due to hydration was balanced by the heat loss to the environment. As shown in Figure 7, the surface temperatures of the air-cured and IoT-based cured samples were very similar such that the temperatures of both sample's temperature did not vary with the exothermic reaction. This is caused by the small concrete sample sizes and the limited time for the exothermic reaction.

Figure 8 shows the measured surface dampness of 3 sets of concrete samples. The initial surface dampness is almost the same for the 3 samples. However, the manual-based curing sample surface dampness rapidly increased from $40 \%$ to $50 \%$ between Time 10 (minutes) and 30 minutes. The reason is the bleeding of water on to concrete surface and the lower evaporation rate due to the plastic film. Afterwards, 


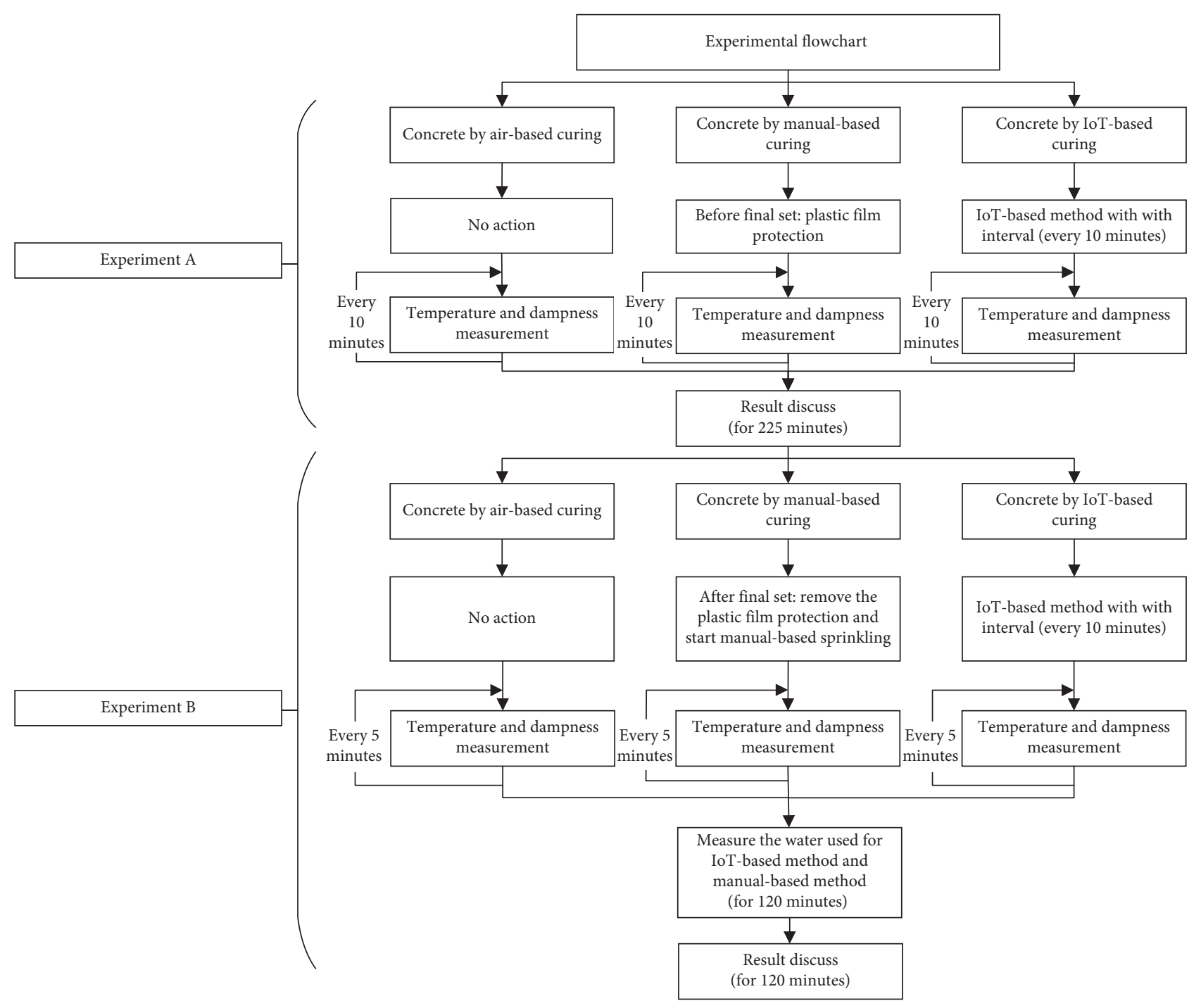

Figure 3: Overview of the experiment.

TABLE 3: Experiment A procedures.

\begin{tabular}{lr}
\hline Steps & \\
\hline 1 & Prepare 3 sets of horizontal fresh concrete $(0.4 \mathrm{~m}$ width $\times 0.3 \mathrm{~m}$ height $\times 0.1 \mathrm{~m}$ depth $)$ \\
3 & Cure 3 sets of concrete by air, IoT device, and hand, respectively \\
4 & Measure and record initial concrete temperature and surface dampness \\
5 & Observe and record the initial appearance of concrete surface
\end{tabular}

Table 4: Experiment B procedures.

\begin{tabular}{lc}
\hline Steps & Starts once 3 sets of samples in Experiment A reach the final set (225 minutes after placing) \\
\hline 1 & Measure and record concrete temperature and surface dampness just after water added both manually and automatically \\
2 & Measure the surface dampness and temperature of the 3 sets of concrete at 5 minute intervals \\
3 & Record the readings \\
4 & Repeat Step 3 until 24 sets of readings have been recorded (2 hours) \\
5 & Measure the water used for IoT-based curing and manual-based curing \\
6 & Compare and discuss the results in Step 5 and Step 6 \\
\hline
\end{tabular}


TABLE 5: Record of concrete surface temperature and dampness in Experiment A.

\begin{tabular}{|c|c|c|c|c|c|c|}
\hline \multirow[b]{2}{*}{ Sample/time } & \multicolumn{3}{|c|}{ Surface temperature } & \multicolumn{3}{|c|}{ Surface dampness } \\
\hline & $\begin{array}{c}\text { Air-based } \\
\text { curing }\left({ }^{\circ} \mathrm{C}\right)\end{array}$ & $\begin{array}{c}\text { IoT-based } \\
\text { curing }\left({ }^{\circ} \mathrm{C}\right)\end{array}$ & $\begin{array}{c}\text { Manual-based } \\
\text { curing }\left({ }^{\circ} \mathrm{C}\right)\end{array}$ & $\begin{array}{l}\text { Air-based } \\
\text { curing (\%) }\end{array}$ & $\begin{array}{l}\text { IoT-based } \\
\text { curing (\%) }\end{array}$ & $\begin{array}{c}\text { Manual-based } \\
\text { curing (\%) }\end{array}$ \\
\hline 0 minutes & 20.1 & 21.6 & 24.8 & 42.6 & 42.5 & 41 \\
\hline 10 minutes & 19.9 & 20.6 & 24.7 & 40.2 & 45.3 & 50 \\
\hline 20 minutes & 19.8 & 20.6 & 24.8 & 41.3 & 45.6 & 50 \\
\hline 30 minutes & 19.9 & 20.6 & 24.5 & 41.0 & 43.6 & 50 \\
\hline 40 minutes & 19.8 & 19.9 & 24.5 & 39.3 & 46.6 & 45.9 \\
\hline 50 minutes & 19.7 & 20.0 & 24.5 & 19.8 & 41.1 & 45.0 \\
\hline 60 minutes & 19.3 & 19.3 & 24.5 & 19.8 & 41.9 & 41.5 \\
\hline 70 minutes & 19.3 & 19.3 & 24.3 & 19.9 & 41.7 & 41.4 \\
\hline 80 minutes & 19.3 & 19.5 & 24.5 & 11.3 & 41.9 & 37.6 \\
\hline 90 minutes & 19.6 & 19.6 & 24.3 & 10.2 & 41.1 & 38.5 \\
\hline 100 minutes & 19.4 & 19.5 & 24.2 & 10.7 & 41.4 & 37.1 \\
\hline 110 minutes & 19.4 & 19.4 & 24.6 & 11.6 & 43.0 & 35.5 \\
\hline 120 minutes & 19.3 & 19.4 & 24.7 & 11.3 & 39.4 & 35.3 \\
\hline 130 minutes & 19.3 & 19.6 & 24.5 & 11.3 & 41.1 & 33.2 \\
\hline 140 minutes & 19.4 & 19.5 & 25.0 & 11.4 & 44.0 & 35.5 \\
\hline 150 minutes & 19.9 & 20.0 & 25.0 & 11.7 & 43.6 & 33.8 \\
\hline 160 minutes & 19.9 & 19.8 & 25.3 & 11.3 & 41.8 & 33.3 \\
\hline 170 minutes & 19.8 & 19.9 & 25.3 & 11.4 & 45.0 & 32.7 \\
\hline 180 minutes & 19.5 & 19.6 & 25.5 & 11.2 & 41.3 & 33.4 \\
\hline 190 minutes & 20.0 & 19.6 & 25.0 & 11.6 & 44.1 & 32.6 \\
\hline 200 minutes & 19.5 & 19.5 & 25.5 & 11.5 & 42.0 & 33.8 \\
\hline 210 minutes & 19.4 & 19.4 & 24.7 & 10.6 & 44.6 & 33.6 \\
\hline 220 minutes & 19.6 & 19.3 & 25.1 & 11.1 & 45.0 & 32.9 \\
\hline 225 minutes & 20.0 & 20.0 & 24.6 & 11.7 & 35.5 & 33.7 \\
\hline
\end{tabular}

TABLE 6: Record of concrete surface temperature and dampness in Experiment B.

\begin{tabular}{|c|c|c|c|c|c|c|}
\hline \multirow[b]{2}{*}{ Sample/time } & \multicolumn{3}{|c|}{ Surface temperature } & \multicolumn{3}{|c|}{ Surface dampness } \\
\hline & $\begin{array}{l}\text { (1) Air-based } \\
\text { curing }\left({ }^{\circ} \mathrm{C}\right)\end{array}$ & $\begin{array}{l}\text { (2) IoT-based } \\
\text { curing }\left({ }^{\circ} \mathrm{C}\right)\end{array}$ & $\begin{array}{l}\text { (3) Manual-based } \\
\text { curing }\left({ }^{\circ} \mathrm{C}\right)\end{array}$ & $\begin{array}{l}\text { (1) Air-based } \\
\text { curing (\%) }\end{array}$ & (2) IoT-based curing (\%) & $\begin{array}{l}\text { (3) Manual-based } \\
\text { curing (\%) }\end{array}$ \\
\hline 5 minutes & 20.0 & 20.0 & 23.9 & 11.6 & 47.5 & 44.1 \\
\hline 10 minutes & 20.0 & 20.0 & 23.2 & 11.6 & 42.3 & 37.6 \\
\hline 15 minutes & 20.0 & 20.0 & 23.4 & 10.3 & 46.8 & 33.6 \\
\hline 20 minutes & 20.1 & 20.0 & 23.2 & 11.5 & 42.7 & 35.4 \\
\hline 25 minutes & 20.1 & 20.1 & 23.2 & 11.5 & 44.8 & 33.0 \\
\hline 30 minutes & 20.2 & 20.2 & 23.1 & 10.9 & 40.9 & 32.9 \\
\hline 35 minutes & 20.1 & 20.1 & 22.5 & 10.5 & 47.6 & 46.6 \\
\hline 40 minutes & 20.0 & 20.0 & 23.1 & 11.7 & 44.1 & 38.4 \\
\hline 45 minutes & 20.3 & 20.0 & 22.7 & 9.6 & 43.8 & 35.2 \\
\hline 50 minutes & 20.1 & 20.1 & 22.4 & 11.8 & 43.3 & 35.8 \\
\hline 55 minutes & 20.0 & 20.0 & 22.3 & 11.5 & 43.3 & 31.6 \\
\hline 60 minutes & 20.5 & 19.9 & 22.3 & 11.4 & 45.2 & 45.1 \\
\hline 65 minutes & 20.5 & 20.0 & 22.1 & 11.5 & 47.6 & 41.2 \\
\hline 70 minutes & 20.5 & 20.3 & 22.0 & 11.4 & 42.5 & 33.3 \\
\hline 75 minutes & 20.5 & 19.7 & 22.0 & 11.2 & 44.3 & 46.2 \\
\hline 80 minutes & 20.5 & 20.4 & 21.9 & 11.3 & 42.1 & 36.1 \\
\hline 85 minutes & 20.0 & 20.3 & 21.1 & 13.5 & 45.2 & 32.2 \\
\hline 90 minutes & 20.4 & 20.0 & 21.0 & 7.9 & 40.0 & 35.4 \\
\hline 95 minutes & 20.4 & 20.3 & 21.0 & 9.2 & 44.0 & 38.7 \\
\hline 100 minutes & 20.1 & 20.2 & 21.0 & 11.4 & 38.5 & 37.6 \\
\hline 105 minutes & 20.9 & 20.2 & 21.0 & 11.6 & 40.0 & 33.2 \\
\hline 110 minutes & 20.5 & 21.0 & 21.0 & 10.6 & 40.3 & 35.9 \\
\hline 115 minutes & 21.0 & 20.3 & 21.0 & 11.6 & 43.2 & 36.9 \\
\hline 120 minutes & 20.9 & 20.4 & 21.0 & 11.7 & 41.4 & 34.1 \\
\hline
\end{tabular}

the surface dampness for the manual-based curing sample dropped gradually from Time 30 (minutes) onwards and reached $33.7 \%$ by the end of Experiment $A$. This is due to the gradual, evaporative, loss of moisture. The surface dampness of air-cured concrete dropped quickly from $42.6 \%$ to $10 \%$. It is observed that the water evaporation rate was high in the case of no curing, especially under continuously windy conditions. The reason for keeping at $10 \%$ dampness is that 
TABLE 7: Manual-based method time.

\begin{tabular}{lr}
\hline Manual-based method times & Manual-based method time at \\
\hline 1 & 05 minutes \\
2 & 35 minutes \\
3 & 57 minutes \\
4 & 72 minutes \\
5 & 93 minutes \\
\hline
\end{tabular}

TABLE 8: Amount of water used by the proposed IoT-based method and manual-based method.

\begin{tabular}{lcc}
\hline Sample/water used & Formula & L \\
\hline 2 IoT-based curing & $\sum$ (sprayed time in seconds $) \times 100 \mathrm{~L} / \mathrm{hr} / 3600 \mathrm{~s}$ & 0.266 \\
3 manual-based curing & $\pi r^{2} \times h \div 1000(r=3.5 \mathrm{~cm}$ and $h=11 \mathrm{~cm})$ & 0.423 \\
\hline
\end{tabular}

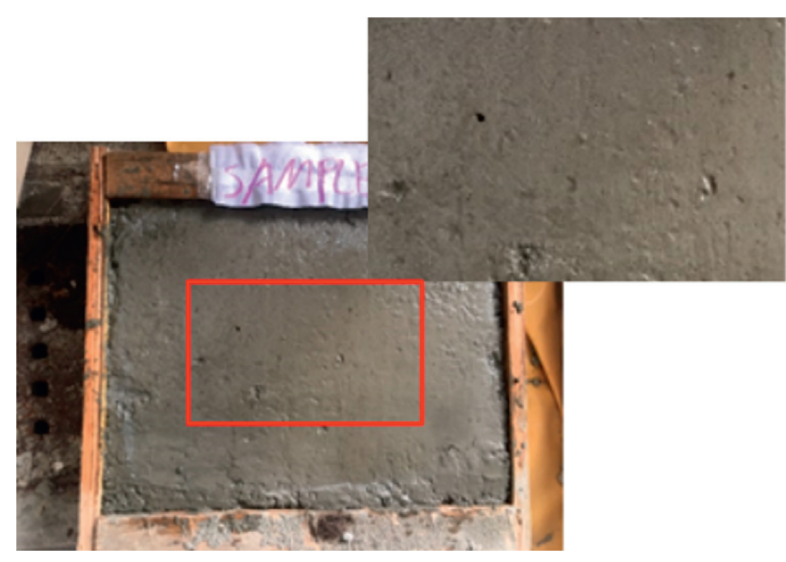

Figure 4: Manual-based curing sample at 225 minutes.

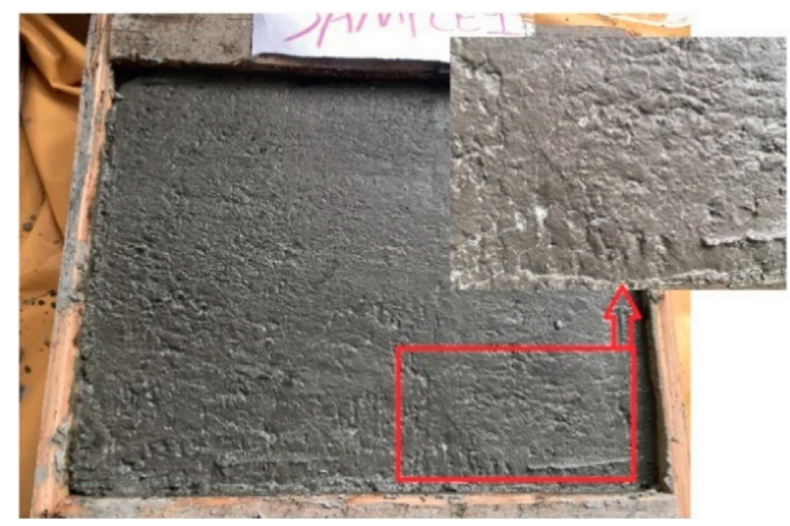

Figure 5: Air-cured sample at 225 minutes.

the water evaporation rate on the concrete surface will equal the flow of capillary water from the centre of the concrete to the surface until all free water within the concrete is lost. The surface dampness of IoT-based concrete remained at $43 \%$ with little fluctuation. According to Figure 8, the initial surface dampness was about $42 \%$. Therefore, a $40 \%$ surface dampness is defined as the minimum dampness for effective curing. While the manual-based curing (plastic film) and air curing could only maintain a surface dampness above $40 \%$

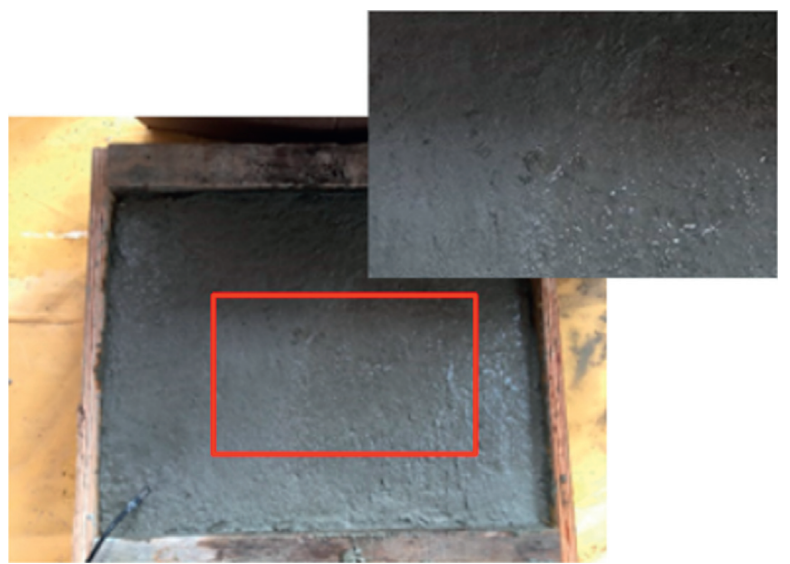

Figure 6: IoT-based cured sample at 225 minutes.

for $31 \%$ ( 70 minutes) and 18\% ( 40 minutes) of the curing time (minutes), IoT-based curing maintained a surface dampness above $40 \%$ for more than $90 \%$ ( 210 minutes) of the curing time. This comparison indicates that manualbased curing (plastic film), compared to air curing, is able to decrease the water evaporation rate and slow down concrete drying. On the contrary, although IoT-based curing cannot slow down the water evaporation rate, it replaces evaporated water continuously to maintain the surface dampness. The surface dampness is almost at a constant level, neither too wet nor too dry.

5.2. Experiment $B$. Figure 9 shows the temperatures of 3 sets of samples after final set (Experiment B). The temperature of the manual-based curing sample dropped in accordance with the time of removal of the plastic film and the start of sprinkling curing. The temperature for air-cured and IoTbased cured samples remains the same as in Experiment A.

Figure 10 shows the measured surface dampness of 3 sets of concrete samples in Experiment B. For air curing, the surface dampness remained the same as for Experiment A.

For manual-based curing and IoT-based curing, both methods were able to maintain the surface dampness of concrete within certain range. However, it is observed that the fluctuation of surface dampness (SSD) is less for 


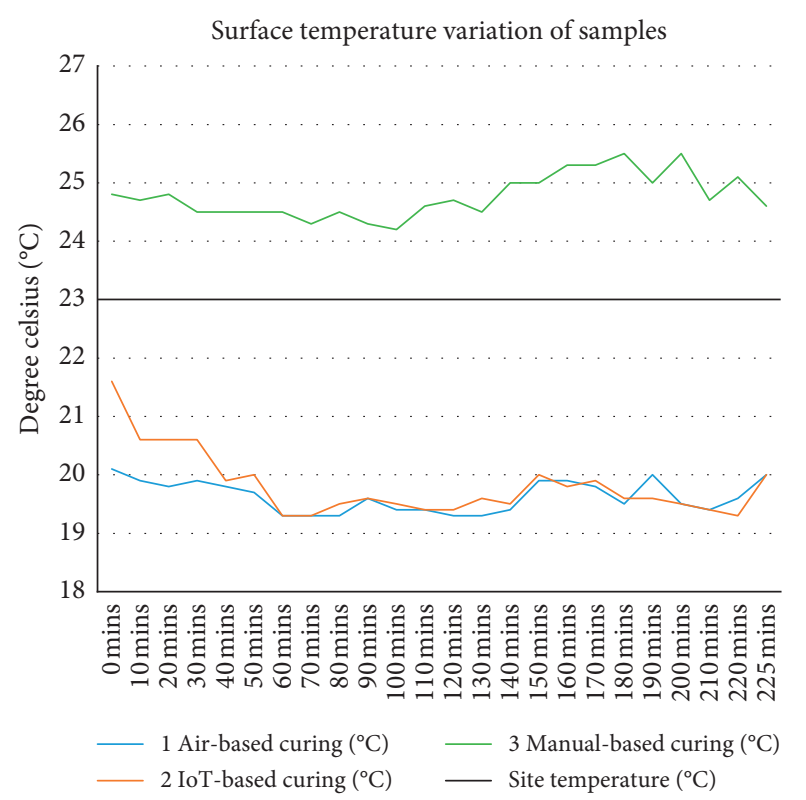

Figure 7: Manually measured surface temperature of 3 sets of concrete.

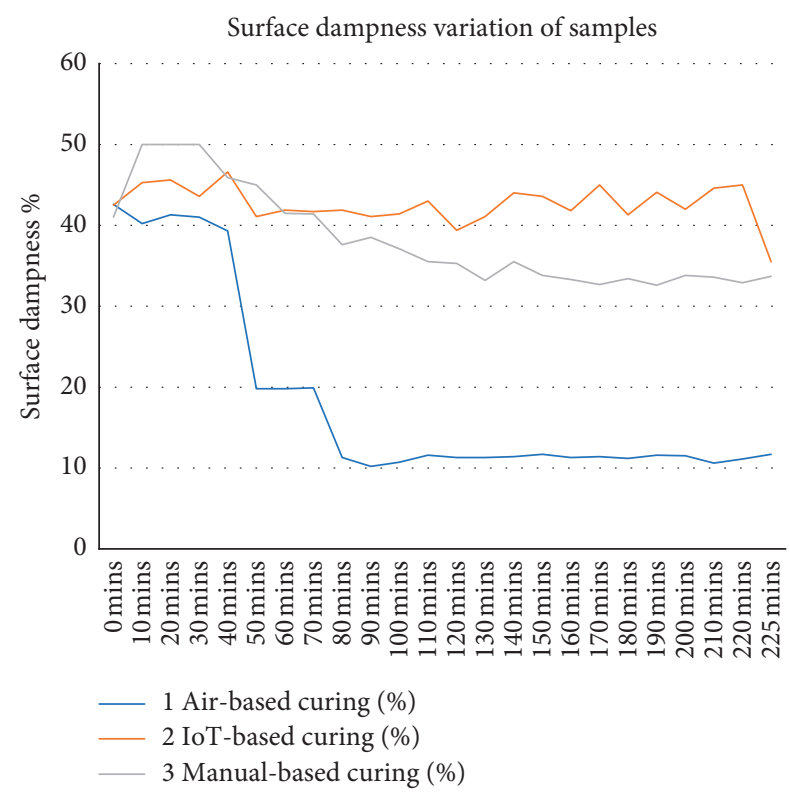

FIGURE 8: Manually measured surface dampness of 3 sets of concrete.

the IoT-based cured sample than for the manual-based curing sample.

The fluctuation rate is defined as the percentage difference between the variation of automatic curing and manual sprinkling (equation (2)). The fluctuation range for IoT-based curing was $9.1 \%$ (equation (3)). The fluctuation range for the manual-based method was $15 \%$ (equation (4)). The fluctuation range for the manual-based method is larger by $64.8 \%$ than for IoT-based curing case (equation (5)):

$$
\text { Fluctuation }=\mathrm{SDD}_{\text {Between automatic curing }}-\frac{\mathrm{SDD}_{\text {Between automatic curing }}}{\mathrm{SDD}_{\text {Between automatic curing }}},
$$

$47.6 \%-38.5 \%=9.1 \%$,

$46.6 \%-31.6 \%=15.0 \%$,

$$
\frac{15 \%-9.1 \%}{9.1 \%}=64.8 \% \text {. }
$$

On the contrary, IoT-based curing maintained concrete surface dampness above $40 \%$ for $96 \%$ of the Time ( 115 minutes), while manual-based method could only maintain concrete surface dampness above $40 \%$ for $25 \%$ of the Time ( $\sim 30$ minutes) after the addition of water. The efficiency of curing is defined by equation (6). The efficiency of curing for IoT-based curing is $95.8 \%$ (equation (7)). The efficiency of curing for manual-based curing is $25 \%$ (equation (8)):

$$
\text { Curing efficiency }=\frac{\text { time above } 40 \% \text { dampness }}{\text { total curing time }}
$$

$$
\begin{aligned}
& \frac{115}{120}=95.8 \%, \\
& \frac{30}{120}=25.0 \% .
\end{aligned}
$$

Therefore, IoT-based curing is $70.8 \%$ more efficient than manual-based curing according to the experiments. A significant difference is due to the continuous wind flow curing condition as well as an inappropriate planning of sprinkler intervals. As a result, the manual-based method water added evaporated rapidly with no further supply of water within a reasonable period. According to equation (9), the water used by manual-based curing was $59.0 \%$ greater than for IoTbased curing:

$$
\frac{0.423-0.266}{0.266} \times 100 \%=59.0 \%
$$

\section{Discussions on Potential Usage of the Invented IoT Device}

6.1. Comparisons of Concrete Curing Technologies in Market. Currently, only a very limited number of technologies facilitate concrete curing. Not for site construction, but for the curing of small concrete items, such as strength test specimens (cylinders and cubes), cast for quality control purposes. They are concrete curing boxes and water tanks [44]. Table 9 contrasts the usage, advantages, and disadvantages using these concrete curing boxes and tanks technologies against the use of the IoT-based concrete curing device for small concrete items cured for long time period. 


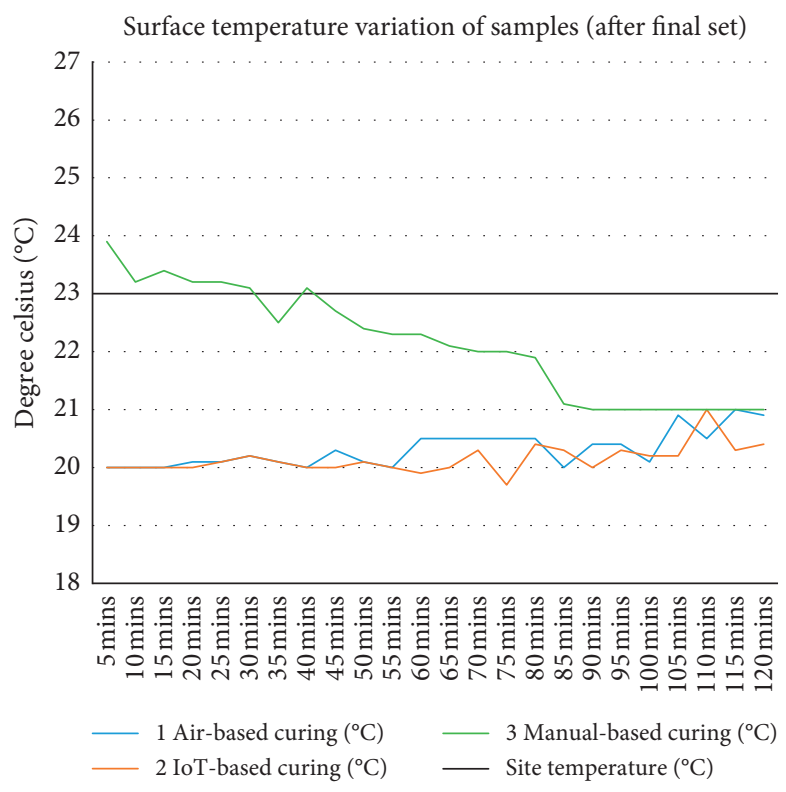

FiguRE 9: Manually measured surface temperature of 3 sets of concrete (after final set).

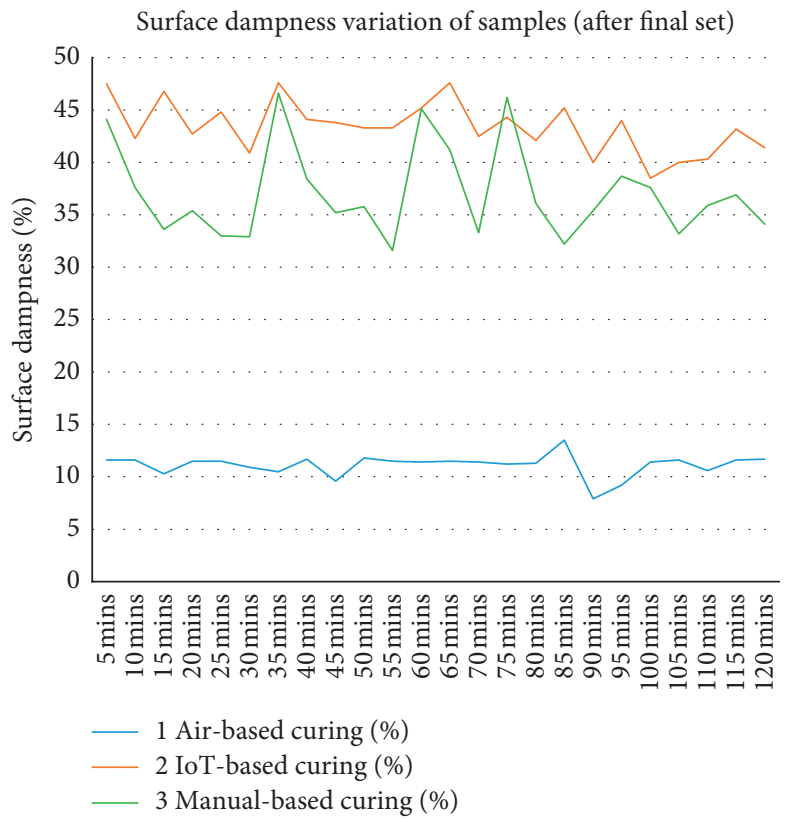

Figure 10: Manually measured surface dampness of 3 sets of concrete.

6.2. Potential of Adopting this Technology in Industrialisation. The technology provides a high accuracy and an efficient way method of concrete curing for structures cast on site. As the sensors and components adopted in this device are of low cost, there is a huge opportunity for its cost-effective industrialised production. This economic and informational-based curing technology can be applied to Enhanced Precast Concrete Components and Modular Integrated Construction (MiC) units. Since both applications employ the factory to produce concrete components, IoT devices might help to cheapen the curing processes in the factory environment by eliminating manual efforts.

There are also difficulties for monitoring and recording the status of prefabricated components, especially for the construction project that with the factory and construction site across countries. The IoT-based concrete curing device can help monitoring and tracking the shipped prefabricated components. The information can be sent automatically to the head office from the prefabricated factories. This may enhance the communications between the stakeholders. 
TABle 9: Curing technologies comparison.

\begin{tabular}{|c|c|c|c|}
\hline Methods & Concrete curing boxes & Concrete curing tanks & IoT-based concrete spraying devices \\
\hline Usage & $\begin{array}{l}\text { Provides continuous storage for long } \\
\text { periods in an environment kept at constant } \\
\text { temperature and high humidity }\end{array}$ & $\begin{array}{l}\text { Provides continuous immersion in } \\
\text { water for long periods; the water } \\
\text { temperature is kept constant }\end{array}$ & $\begin{array}{l}\text { Spraying water as necessary to } \\
\text { provide a constant concrete water } \\
\text { content over time }\end{array}$ \\
\hline Advantages & $\begin{array}{l}\text { Reliable all-round control of concrete test } \\
\text { specimen's environment }\end{array}$ & $\begin{array}{l}\text { Cost-effective alternative to specimen } \\
\text { environmental control; a set water } \\
\text { temp. } 100 \% \mathrm{RH}\end{array}$ & $\begin{array}{l}\text { Adaptable, cost-effective alternative } \\
\text { to full-scale on-site concrete } \\
\text { Combined monitoring and } \\
\text { analysing function to decide the } \\
\text { amount of water spray }\end{array}$ \\
\hline Disadvantages & Only applied for small-sized concrete & $\begin{array}{l}\text { Only used for small-sized concrete } \\
\text { pieces; usually quality control test } \\
\text { specimens }\end{array}$ & $\begin{array}{l}\text { Specimens monitored should not be } \\
\text { in direct sunlight, as radiation } \\
\text { effects are not allowed for }\end{array}$ \\
\hline
\end{tabular}

Human errors and bias when recording the concrete qualities can be avoided.

To install the Enhanced Precast Concrete Components on site, the semi-prefabricated components (slabs, walls, staircases, and facades) require in situ concrete sealing at component connections. By adopting the invented IoT device, a more accurate and time-saving curing process can be performed. Thus, these innovative IoT-based concrete curing methods can lead to better and more economical curing on site than the traditional one.

6.3. Limitations of Using the Proposed IoT Device for Curing Concrete. As the current IoT device takes no account of the effect of radiation, curing accuracy is affected by direct sunlight. It is suggested that a radiation sensor should be added to allow for calculating its effect on water evaporation based on the combination formula shown below $[6,45]$. However, the formula derived by Penman requires that the water temperature is equal to air temperature:

$$
\text { Total evaporation }=\left(\frac{Q_{n} \times \Delta+\gamma \times E_{a}}{(\Delta+\gamma)}\right),
$$

where $E=$ total evaporation, $\Delta=$ slope of the saturation curve = $4098 \times e_{s} /(237.3+T)^{2}$, where $e_{s}=0.61 e^{(17.3 T) /(237.3+T)}, \gamma=$ psychrometric constant, $=0.066 \mathrm{kPa} / \mathrm{C}, Q_{n}=$ solar radiation, and $E_{a}=$ evaporation from aerodynamic formulas (water loss calculation embedded into the current proposed device).

\section{Conclusions}

Currently, concrete curing on site involves labour intensive and time-consuming procedures. Since the curing process required workers to use much water and time in maintaining good environmental conditions to protect newly cast concrete, the process is regarded as nonsustainable, wasteful, and of low productivity. It also puts additional burden on the contractor which the use of IoT instead might relieve somewhat. Even if the traditional process is carried out by workers of experience and determination, it is difficult to ensure that curing is precise and accurate enough. The amount of water to spray on concrete is a subjective judgement and inevitably differs from person to person.
This research study indicated the potential for IoT devices to improve the accuracy and efficiency of concrete curing. The proposed IoT device studied here monitors the environmental conditions and the water lost from the curing concrete in real time. As the amount of replacement water sprayed on the concrete surface is calculated in accordance with ambient environmental conditions, the already hydrated, and vulnerably weak cement paste matrix, will no longer be at risk of an excessive water load inflow. The water spent during the process and the environmental condition can be recorded automatically for further analysis. Information will be sent to a computer platform for data sharing without any human intervention, for intercommunication purposes. Hence, the head office can collect the data effectively through the computer platform, and the decision makers are alerted only if some changes anomaly in the call for water by the curing concrete emerges. The device eliminates the large quantities of water and manpower required by the traditional manual-based curing method. The experiments performed showed that the IoT device reduced construction workload and enhanced work productivity, indicating that the device is a viable alternative to traditional curing on that account.

At the more detailed level-is the curing performance achieved by the IoT device up to the standards achieved by the traditional methods? The results for manual-based curing and IoT-based curing showed similar effects in maintaining the surface moisture (42\%) initially in Experiment A. However, IoT-based curing was able to maintain the surface moisture at a more constant level than manual-based curing for a longer period. The surface moisture content of the manual-based curing sample would drop slightly by $5 \%$ (to $35 \%$ ). By observation, comparing the surface appearances of three sets of samples, it is proven that IoT-based curing more successfully avoids plastic shrinkage cracking before the final concrete set.

The experiment results validated that the new IoT-based concrete curing method keeps the concrete surface dampness more constant and predictable compared to the manual-based method since the alternate drying-wetting effect was minimized in Experiment B (fluctuation range improved by $64.8 \%$ with $>90 \%$ efficiency rate). Furthermore, 
the quantity of water used for IoT-based concrete curing was less than for manual-based concrete curing with better accuracy and efficiency (59\% water saving).

However, the current IoT concrete curing device does not allow for the effect of radiation, so curing accuracy is affected by direct sunlight. Future research will enhance the IoT device with a radiation sensor linked to Penman's combination formula as a factor governing the evaporation rate. Determining the optimal formulas for other types of concrete mixture when using the IoT-based concrete curing device is also recommended for further research.

\section{Data Availability}

The data used to support the findings of this study are available from the corresponding author upon request.

\section{Conflicts of Interest}

The authors declare that there are no conflicts of interest regarding the publication of this paper.

\section{Acknowledgments}

This work was supported by UGC-Funded Research Postgraduate (RPg) Programmes and Hong Kong Polytechnic University that provided grant for supporting the research project "Data-Driven Resource Planning for Building Works in Hong Kong" (P0000215/BE0S) and "A Study of Project Performance (Productivity, Safety, Quality, Environment) Using Worker Records in Hong Kong Building Construction" (P0009759/YBZF). Special thanks to Prof. Mike Anson, Ms. Sandy Lam, and Mr. Leo Wong for their advices in editing the manuscript.

\section{References}

[1] Building Department, "Code of practice for structural use of concrete 2013," 2013, https://www.bd.gov.hk/doc/en/resource s/codes-and-references/code-and-design-manuals/CoP_SUC 2013e.pdf.

[2] American Concrete Institute Committee, "Guide to curing concrete,” 2008, http://dl.mycivil.ir/dozanani/ACI/ACI\%203 08R-01\%20R08\%20Guide\%20to\%20Curing\%20Concrete_My Civil.ir.pdf.

[3] Y. Tang, H. Su, S. Huang, C. Qu, and J. Yang, "Effect of curing temperature on the durability of concrete under highly geothermal environment," Advances in Materials Science and Engineering, vol. 2017, Article ID 7587853, 9 pages, 2017.

[4] A. S. Shaikh, P. S. Lahare, V. B. Nagpure, and S. S. Ghorpde, "Curing of concrete," International Research Journal of Engineering and Technology, vol. 04, no. 3, pp. 913-917, 2017, https://www.irjet.net/archives/V4/i3/IRJET-V4I3231.pdf.

[5] Victorian State Road Authority, Curing of Concrete, Vol. 42, Victorian State Road Authority, Burwood, Australia, 2000.

[6] P. Uno, "Plastic shrinkage cracking and evaporation formulas," ACI Materials Journal, vol. 95, pp. 365-375, 1998.

[7] D. W. Gawatre, K. Sawant, R. Mule, N. Waydande, D. Randeve, and T. Shirsath, "Effectiveness of curing compound on concrete," IOSR Journal of Mechanical and Civil Engineering, vol. 14, no. 3, pp. 73-76, 2017.
[8] A. Goel, J. Narwal, V. Verma, D. Sharma, and B. Singh, “A comparative study on the effect of curing on the strength of concrete," International Journal of Engineering and Advanced Technology, vol. 2, no. 6, pp. 401-406, 2013, https://www.ijeat. org/wp-content/uploads/papers/v2i6/F2116082613.pdf.

[9] R. Krishna, R. Kumar, and A. Khan, "A study on the influence of curing on the strength of a standard grade concrete mix," Facta Universitatis - Series: Architecture and Civil Engineering, vol. 8, no. 1, pp. 23-34, 2010.

[10] S. Rubene and M. Vilnitis, Impact of Low Temperatures on Compressive Strength of Concrete, Riga Technical University, Riga, Latvia, 2017.

[11] B. Mather, "Discussion by mather on paper by Zawde Berhane, (1985) "evaporation of water from fresh mortar and concrete at different environmental conditions," Journal of the American Concrete Institute, vol. 26, no. 2, pp. 931-932, 1985.

[12] K.-H. Yang, J.-S. Mun, and M.-S. Cho, "Effect of curing temperature histories on the compressive strength development of high-strength concrete," Advances in Materials Science and Engineering, vol. 2015, Article ID 965471, 12 pages, 2015.

[13] J. Fladr and I. Broukalova, "Influence of curing temperature on the mechanical properties of high-performance concrete," IOP Conference Series: Materials Science and Engineering, vol. 583, Article ID 12011, 2019.

[14] A. V. Kalbande, A. G. Chavan, and F. H. Khan, "Membrane curing of concrete," International Journal of Advance Engineering and Research Development, vol. 4, no. 5, pp. 11-15, 2017, http://www.ijaerd.com/papers/finished_papers/ Membrane\%20Curing\%20Of\%20ConcreteIJAERDV04I0592647.pdf.

[15] K. P. Princy and J. Elson, "Study on the effectiveness of various curing methods on the properties of concrete," International Journal of Engineering Research And, vol. 4, no. 11, pp. 213216, 2015.

[16] S. Ghourchian, M. Wyrzykowski, and P. Lura, "A practical approach for reducing the risk of plastic shrinkage cracking of concrete," RILEM Technical Letters, vol. 2, pp. 40-44, 2017.

[17] T. James, A. Malachi, E. Gadzama, and A. Anametemok, "Effect of curing methods on the compressive strength of concrete," Nigerian Journal of Technology, vol. 30, pp. 14-20, 2011.

[18] Y. Nahata, N. Kholia, and T. G. Tank, "Effect of curing methods on efficiency of curing of cement mortar," APCBEE Procedia, vol. 9, pp. 222-229, 2014.

[19] G. M. Di Giuda, A. Gottfried, P. Piantanida, and V. Villa, "Monitoring construction site buildings with concrete structures," in Proceedings of the Modern Methods and Advances in Structural Engineering and Construction, Singapore, June 2011.

[20] M. Kotb, M. I. A. Razik, and Y. S. Al-Alyan, "A standard framework for effective progress reports in the state of Kuwait," American Journal of Operations Research, vol. 8, no. 1, pp. 42-49, 2018.

[21] E. K. Owusu and A. P. Chan, Corruption in Infrastructure Procurement: Addressing the Dynamic Criticalities, Routledge, London, UK, 2020.

[22] P. Gokhale, O. Bhat, and S. Bhat, "Introduction to IOT," International Advanced Research Journal in Science, Engineering and Technology, vol. 5, pp. 41-44, 2018.

[23] V. Arslan, S. Ulubeyli, and A. Kazaz, "The use of internet of things in the construction industry," in Proceedings of the 4th 
International Energy \& Engineering Congress, Gaziantep, Turkey, October 2019.

[24] W. Z. Taffese, E. Nigussie, and J. Isoaho, "Internet of things based durability monitoring and assessment of reinforced concrete structures," Procedia Computer Science, vol. 155, pp. 672-679, 2019.

[25] A. Ghosh, M. R. Hosseini, R. Al-Ameri, G. Kaklauskas, and B. Nikmehr, "Internet of Things (IoT) for digital concrete quality control (DCQC): a conceptual framework," in Proceedings of the 13th International Conference Modern Building Materials, Structures and Techniques, pp. 298-305, Vilnius, Lithuania, May 2019.

[26] H. Klee, The Cement Sustainability Initiative: Recycling concrete, World Business Council for Sustainable Development, Geneva, Switzerland, 2009.

[27] Australian Government, Productivity and Income-the Australian story, Shifting the Dial: 5 Year Productivity Review (Supporting Paper No. 1), Planning Commission, Perth, Australia, 2017.

[28] J. Yang, J. Fan, B. Kong, C. S. Cai, and K. Chen, "Theory and application of new automated concrete curing system," Journal of Building Engineering, vol. 17, pp. 125-134, 2018.

[29] B. Klemczak and A. Jędrzejewska, "Early age thermal and shrinkage cracks in concrete structures - description of the problem," Architecture Civil Engineering Environment, vol. 4, pp. 35-47, 2011.

[30] N. R. Kholia, B. A. Vyas, and T. G. Tank, "Effect on concrete by different curing method and efficiency of curing compounds-a review," International Journal of Advanced Engineering Technology, vol. IV, no. II, pp. 57-60, 2013, https:// www.technicaljournalsonline.com/ijeat/VOL\%20IV/IJAET\% 20VOL\%20IV\%20ISSUE\%20II\%20APRIL\%20JUNE\%202013 /Vol\%20IV\%20Issue\%20II\%20Article\%2015.pdf.

[31] "Anemometer with arduino uno-arduino livecast S03E03," 2019, https://www.youtube.com/watch?v=IN4w6m3D3PY.

[32] Arcaegecengiz, "Using DHT11," 2018, https://create.arduino. $\mathrm{cc} /$ projecthub/arcaegecengiz/using-dht11-b0f365.

[33] Arduino, "What is Arduino?," 2020, https://www.arduino.cc/ en/Guide/Introduction/.

[34] Arduino, "Tutorials," 2020, https://www.arduino.cc/en/Tutor ial/HomePage/.

[35] S. Campbell, "How to set up a 5V relay on the arduino," 2020, https://www.circuitbasics.com/setting-up-a-5v-relay-on-thearduino/.

[36] K. Dimitrov, "DS18B20 (digital temperature sensor) and arduino," 2016, https://create.arduino.cc/projecthub/TheGadgetBoy/ ds18b20-digital-temperature-sensor-and-arduino-9cc806.

[37] B. Earl, "Multi-tasking the arduino-part 1," 2014, https:// learn.adafruit.com/multi-tasking-the-arduino-part-1/usingmillis-for-timing.

[38] Instructables, "Two ways to reset arduino in software," 2017, https://www.instructables.com/two-ways-to-reset-arduinoin-software/.

[39] M. James, "Doing multiple timed things with arduino: unleash the millis!," 2019, https://www.programmingelectronics.com/ arduino-millis-multiple-things/.

[40] L. Louis, "Working principle of arduino and using it as a tool for study and research," International Journal of Control, Automation, Communication and Systems, vol. 1, no. 2, pp. 21-29, 2016.

[41] D. V. Mallikarjuna Reddy and S. Hamsalekha, "Smart concrete curing system," E3S Web of Conferences, vol. 184, no. 3, Article ID 01086, 2020.
[42] Paskino, "Simple data statistics (temperature)," 2016, https:// create.arduino.cc/projecthub/paskino/simple-data-statisticstemperature-c2d77c.

[43] A. G. Smith, "Introduction to arduino," 2011, http://www. introtoarduino.com/downloads/IntroArduinoBook.pdf.

[44] Gilson, Company. InC, "Concrete curing equipment," 2021, https://www.globalgilson.com/concrete-curing.

[45] Libelium, "Solar radiation sensor," 2020, https://www. cooking-hacks.com/solar-radiation-sensor.html. 